Human Mutation

WILEY

\title{
Mosaic type-1 NF1 microdeletions as a cause of both generalized and segmental neurofibromatosis type-1 (NF1)
}

\begin{tabular}{|r|l|}
\hline Journal: & Human Mutation \\
\hline Manuscript ID: & humu-2010-0440.R1 \\
\hline Datey - Manuscript type: & Research Article \\
\hline Author: & $19-$ Oct-2010 \\
\hline Complete List of Authors: & $\begin{array}{l}\text { Messiaen, Ludwine; University of Alabama at Birmingham, } \\
\text { Department of Genetics } \\
\text { Vogt, Julia; University of Ulm, Human Genetics } \\
\text { Bengesser, Kathrin; University of Ulm, Human Genetics } \\
\text { Fu, Chuanhua; University of Alabama at Birmingham, Department } \\
\text { of Genetics } \\
\text { Mikhail, Fady; University of Alabama at Birmingham, Department of } \\
\text { Genetics } \\
\text { Serra, Eduard; IMPPC, Hereditary Cancer Program } \\
\text { Garcia-Linares, Carle;; IMPPC, Hereditary Cancer Program } \\
\text { Cooper, David; Cardiff University, Institute of Medical Genetics, } \\
\text { College of Medicine } \\
\text { Lázaro, Conxi; Catalan Institute of Oncology (ICO), Translational } \\
\text { Research Laboratory } \\
\text { Kehrer-Sawatzki, Hildegard; University of Ulm }\end{array}$ \\
\hline Key Words: & $\begin{array}{l}\text { Neurofibromatosis type 1, mosaicism, microdeletion, recombination } \\
\text { hotspots, segmental neurofibromatosis }\end{array}$ \\
\hline \hline
\end{tabular}

\section{SCHOLARONE \\ Manuscripts}


1

3

4

5

6

7

8

9

Mosaic type-1 NF1 microdeletions as a cause of both generalized and segmental neurofibromatosis type-1 (NF1)

Ludwine Messiaen ${ }^{1}$, Julia Vogt ${ }^{2}$, Kathrin Bengesser ${ }^{2}$, Chuanhua $\mathrm{Fu}^{1}$, Fady Mikhail ${ }^{1}$, Eduard

Serra ${ }^{3}$ Carles Garcia-Linares ${ }^{3}$ David N. Cooper ${ }^{4}{ }^{4}$ Conxi Lazaro $\frac{5}{9}$ Hildegard Kehrer-

Sawatzki ${ }^{2}$

1: Medical Genomics Laboratory, Department of Genetics, University of Alabama at

Birmingham, Birmingham, Alabama, USA

2: Institute of Human Genetics, University of Ulm, Ulm, Germany

3: Institut de Medicina Predictiva i Personalitzada del Càncer (IMPPC), Badalona, Barcelona, Spain

4: Institute of Medical Genetics, School of Medicine, Cardiff University, Cardiff, UK

5. Programa de Cáncer Hereditari, Unitat de Diagnòstic Molecular, Laboratori de Recerca

Translacional, Institut Català d'Oncologia-Institut d'Investigació Biomèdica de Bellvitge

(IDIBELL), L'Hospitalet de Llobregat, Barcelona, Spain

Corresponding author:

Hildegard Kehrer-Sawatzki

Institute of Human Genetics, University of Ulm

Albert-Einstein-Allee 11, 89081 Ulm, Germany

Phone: 004973150065421 , FAX: 004973150065402

Email: hildegard.kehrer-sawatzki@uni-ulm.de

Key Words: Neurofibromatosis type $1(N F 1)$ gene, microdeletion, recombination hotspots, mosaicism, segmental neurofibromatosis

\begin{tabular}{l} 
Deleted: ${ }^{4}$ \\
Deleted: ${ }^{4}$ \\
${\text { Deleted: }{ }^{5}}{ }^{4}$ \\
\hline
\end{tabular}

Deleted: 4: Departament de Genètica, Institut d'Investigació Biomèdica de Bellvitge (IDIBELL), L'Hospitalet de Llobregat, Barcelona, SpainđI

Deleted: 5

Deleted: 6 
Deleted: existence

Deleted: of

Deleted: deletions and

Two of the 4 probable type- 1 deletions were confirmed as such by breakpoint-spanning PCR or SNP analysis. Both deletions were associated with a generalized manifestation of NF1. Independently, we identified a third patient with a mosaic type-1 NF1 deletion who exhibited segmental NF1. Together, these three cases constitute the first proven mosaic type-1 deletions so far reported. In two of these three mosaic type-1 deletions, the breakpoints were located within PRS1 and PRS2, previously identified as hotspots for non-allelic homologous recombination (NAHR) during meiosis. Hence, NAHR within PRS1 and PRS2 is not confined to meiosis but may also occur during postzygotic mitotic cell cycles. 


\section{Introduction}

Neurofibromatosis type 1 (NF1; MIM \#162200) is a common neurocutaneous disorder with an estimated birth incidence of 1/3000 [Friedman et al., 1999; Lammert et al., 2005].

Characteristic clinical symptoms include multiple café-au-lait spots, skinfold freckling, Lisch nodules and neurofibromas. Large deletions of the entire NF1 gene and its flanking regions (also termed NF1 microdeletions) are observed in $\sim 5 \%$ of all patients with neurofibromatosis type 1 (NF1) [Kluwe et al., 2004]. Four types of large NF1 deletion (type-1, type-2, type-3 and atypical) have been identified, which differ with respect to the extent of the deleted region and the location of the respective breakpoints. The most frequent NFl deletion is type-1 which encompasses 1.4-Mb and includes 14 genes. The breakpoints of type- 1 deletions are invariably located within low-copy repeats, termed NF1-REP A and NF1-REP C, which flank the NF1 gene region [Dorschner et al., 2000; Jenne et al., 2001; Lopéz-Correa et al., 2001]. Most type-1 NF1 deletions are caused by non-allelic homologous recombination (NAHR) occurring within two recombination hotspots, termed paralogous recombination sites 1 and 2 (PRS1 and PRS2) located within NF1-REPs A and C [Forbes et al., 2004; De Raedt et al., 2006]. By contrast, type-2 NF1 deletions encompass 1.2-Mb; their breakpoints are located within the SUZ12 gene and its pseudogene $S U Z 12 P$, located adjacent to the NF1-REPs [Petek et al., 2003; Kehrer-Sawatzki et al., 2004; Steinmann et al., 2007; Roehl et al., 2010a]. The major mechanism underlying type-2 NF1 deletions is NAHR [Roehl et al., 2010b]. In addition to type-1 and type-2 deletions, a third recurrent type of NF1 deletion has recently been identified which is also mediated by NAHR. These type-3 deletions span $1.0-\mathrm{Mb}$, with breakpoints located within NF1-REP B and NF-REP C [Bengesser et al., 2010; Pasmant et al., 2010]. In contrast to the aforementioned recurrent $N F 1$ deletions mediated by NAHR, the so called "atypical" NF1 deletions are neither mediated by homology-based mechanisms nor are they recurrent with respect to the localization of their breakpoints. Consequently, atypical 
$N F 1$ deletions can differ quite markedly from each other in terms of the number of deleted genes [Kehrer-Sawatzki et al., 2008 and references therein; Pasmant et al., 2008, 2010]. NF1 microdeletions are often associated with severe disease manifestations including a high tumour load, facial dysmorphism and mental retardation [Mensink et al., 2006; Venturin et al., 2006; Mautner et al., 2010; Pasmant et al., 2010].

Somatic mosaicism is an important issue in NF1 because it influences the phenotypic expression of the disease, its recurrence as well as its transmission risk [Erickson, 2010; Gottlieb et al., 2001; Kehrer-Sawatzki and Cooper, 2008; Youssoufian and Pyeritz, 2002]. Most patients with mosaic NF1, jn whom causative NF1 mutations have been identified, Deleted: whose possess large deletions of the $N F 1$ gene region. This excess of deletions is probably due to an ascertainment bias since mosaic $N F 1$ microdeletions are relatively easy to identify at the individual cell level using FISH analysis. By contrast, the detection of mosaicism for a nucleotide substitution within the $N F 1$ gene is much more difficult, particularly if cells bearing the mutation are present at low levels [Maertens et al., 2007]. So far, the majority of reported mosaic NF1 microdeletions have been either atypical or type-2 [reviewed in KehrerSawatzki and Cooper, 2008]. _Although 80\% of NF1 deletions are type-1 [Dorschner et al., 2000; Pasmant et al., 2010], only one solitary example of a putative mosaic type-1 NF1 deletion has so far been reported [De Luca et al., 2007]. This deletion was not unequivocally shown to be type-1 since the extent of the deletion was determined solely by multiplex ligation-dependent probe amplification (MLPA). The MLPA-kit available at that time, and used by De Luca et al. [2007], did not include any MLPA_probes located outside the 1.4-Mb type-1 NFI deletion region. Consequently, MLPA could not differentiate between a 1.4-Mb deletion and a larger, atypical deletion. Likewise, the currently available MLPA-kit (P122, version C1) cannot provide the degree of resolution required to distinguish between type-1 NFI deletions (with breakpoints in the NF1-REPs) and atypical deletions with breakpoints located close to, but 
outside of, the NF1-REPs A and C as outlined previously [Mautner et al., 2010]. Such atypical deletions could also encompass the GOSR1, TBC1D29, RHOT1, RHBDL3 and C17orf75 genes in addition to the 14 genes present within the type-1 deletion interval (Figure 1A). Our current knowledge of atypical deletions should potentiate the improved positioning of probes in future MLPA-kits, an important issue since atypical deletions are present in $\sim 10 \%$ of patients with large NF1 deletions [Pasmant et al., 2010; this study].

The erstwhile absence of confirmed mosaic type-1 NF1 deletions raised the question as to whether type-1 deletions might be confined to the germline. This prompted us to undertake an extensive search for this type of deletion and to determine its relative frequency. Beyond the intrinsic importance of mosaicism itself, the existence of mosaic type-1 deletions would serve to demonstrate that NAHR between the highly homologous NF1-REPs A and C is not confined to the germline but might also occur during postzygotic mitotic cell cycles.

\section{Patients and Methods}

In this study, we identified 5 putative mosaic type- 1 NFI deletions and then proceeded to analyse the extent of each deletion in detail. This study was approved by the Institutional Review Boards of the participating institutions. Four of these mosaic deletions (those in patients UAB-M1, UAB-r3302, UAB-r7332 and UAB-r3222) were identified in a cohort of 3500 unrelated NF1 patients investigated by comprehensive NF1 mutation analysis performed at the Medical Genomics Laboratory, Department of Genetics, University of Alabama at Birmingham, as described [Messiaen and Wimmer, 2008]. The fifth patient, P067, was identified during the course of a loss of heterozygosity $(\mathrm{LOH})$ analysis that included 518 dermal neurofibromas from 113 patients with NF1 [Garcia-Linares et al., 2010]. 


\section{Individual case reports}

Patient UAB-M1

This 14-year-old white American boy exhibited three café-au-lait spots and freckling/

hyperpigmentation on the left upper thigh. Freckling in the left inguinal region was also

noted. Since only the left upper thigh/inguinal region was affected, the patient was considered

to exhibit segmental NF1. No dermal, subcutaneous or plexiform neurofibromas were

observed. The presence of Lisch nodules or asymptomatic optic gliomas were not

investigated. Developmental delay was not observed. Melanocytes and fibroblasts were

successfully cultured from a biopsy of one of the patient's café-au-lait spots, as described

[Maertens et al., 2007]. cDNA and genomic DNA derived from both cell types were

investigated by sequencing of $N F 1$ exons and MLPA, respectively. A blood sample from this patient could not however be obtained for further testing.

Patient UAB-r3302

This 15-year-old boy of Asian origin had $>6$ café-au-lait spots, axillary freckling and cutaneous neurofibromas on the left neck, arm and trunk region. Furthermore, he had a plexiform neurofibroma on the left arm (with bluish overlying skin). Despite the fact that he was affected mainly on his left body side, a localized segmental manifestation was deemed unlikely since freckling and a few café-au-lait spots were also noted on the right arm and hand. Bilateral Lisch nodules were also diagnosed. Spinal neurofibromas and optic gliomas were absent as determined by MRI. Skeletal abnormalities were also absent. cDNA and genomic DNA isolated from venous blood was investigated by MLPA, FISH and PCR to assess heterozygosity.

Patient UAB-r7332

This 10-year-old white American boy exhibited multiple (>6) café-au-lait spots, bilateral 


\section{Patient P067}

This 45-year-old white Spanish female patient exhibited a rather localized manifestation of symptoms compatible with a diagnosis of segmental NF1. She had 20 small dermal

neurofibromas as well as freckling on her upper right back and below the right breast (Supp Figure S1). Inguinal but not axillary freckling was noted, Café-au-lait spots and Lisch nodules were not observed. The patient suffered from severe hypertension. Facial dysmorphic features, developmental delay or learning disabilities were not noted. The patient had an IQ of 99. DNA samples were isolated from blood, saliva, two neurofibromas and the skin overlying these neurofibromas in order to perform deletion breakpoint-spanning PCRs. FISH analysis was not performed.

\section{Methods}


Multiplex Ligation-dependent Probe Amplification (MLPA)

DNA was isolated from venous blood samples of the patients using the Qiamp kit (Qiagen,

Valencia, CA, USA). Large deletions of the NF1 gene and its flanking regions were identified using the SALSA P122 C1 MLPA assay (MRC-Holland, Amsterdam, Netherlands) according to the manufacturer's instructions and as described by Wimmer et al., [2006].

Microsatellite marker analysis

In addition to MLPA, four microsatellite markers located within the NF1 gene region (IVs27GXAlu, IVs27TG24.8, IVs27AC28.4, IVs38TG53.0) were analysed by PCR in all 3500 NF1

Fluorescence in situ hybridization (FISH)

Where MLPA or microsatellite marker analysis gave any hint as to the presence of a deletion with or without mosaicism with normal cells, interphase FISH was performed on 200 uncultured blood cells using probes RP5-1002G3 (detected by red fluorescent signals) and RP5-926B9 (green). If the proportion of normal cells was very low ( $>0 \%$ and $>5 \%), 400$ interphase nuclei were evaluated. Probe RP5-1002G3 (GenBank accession no.: CG786083) is located in the telomeric region of the NF1 gene, whereas FISH probe RP5-926B9 spans the centromeric part of the NF1 gene [De Raedt et al., 2004]. The genomic region encompassed by these FISH probes is $\sim 150-\mathrm{kb}$. Thus, two red/green fusion FISH signals should be obtained from an interphase nucleus with two normal chromosomes 17 lacking the $N F 1$ deletion. The centromere-specific alpha satellite probe D17Z1 was used as a reference FISH probe from outside of the NF1 deletion region (CEP17 Spectrum-Aqua, Vysis, Abbott Molecular Inc., Illinois, USA). Owing to the use of two test probes located within the NF1 gene region, our 
assay is well suited to exclude consideration of wrongly assigned normal cells because it is highly unlikely that both of the two test probes would yield false positive signals. In no case was the occurrence of only one normal cell (versus 199 cells with the deletion).observed in our assays.

Breakpoint-spanning PCR (deletion junction assays)

To detect type-1 NF1 deletions with breakpoints located within the PRS1 and PRS2 hotspots, breakpoint-spanning PCRs were performed using the Expand Long Template PCR system (Roche, Penzberg, Germany) with 400 ng genomic DNA isolated from whole blood samples as template. The primers used for these deletion junction PCRs are listed in Supp $\mathrm{T}_{\longleftarrow}$ Table $\mathrm{S} 1$. Positive PCR products of 2.9-kb and 3.5-kb were sequenced from both ends. The analysis of the paralogous-specific sequence variants that distinguish NF1-REP A and NF1-REP C indicated whether the PCR products were true positive recombinant deletion junction fragments. In addition to PRS1 and PRS2, we also investigated the breakpoint region identified in a single patient (UWA160-1) as reported by Forbes et al., [2004] using primers 160P1-F (5'-GGCTCATGTGTAATGATCTTTAACGCG-3') and MD1-R(v2) (5'CAAAGATTATCACTGATGGAGTTGG-3’) (Supp _. Figure S2).

All DNA samples were pre-tested by PCR to determine if the DNA was of sufficient quality for robust amplification of large DNA fragments. For this purpose, we used primers17s1 (5' CAAGGCAACAAACTGAAGCA 3') and tg5 (5' TCCATTTGCTGTCCCATTTT 3') to amplify a 5-kb fragment from 17q12. Positive PCR products using these primers confirmed that long PCR products could be amplified from the respective DNA sample and that negative breakpoint-spanning PCRs were not due to low template DNA quality.

Single nucleotide polymorphism (SNP) analysis

Deleted: lementary 
The extent of those deletions that were negative in the deletion junction assays was further

investigated by SNP analysis using PCR (primers listed in Supp _ Table S2). The respective

PCR products were sequenced and analysed by BLAT sequence alignments

(http://genome.ucsc.edu/) to avoid confusion between paralogous sequence differences and SNPs.

\section{Results}

MLPA, microsatellite marker analysis and FISH were used in concert to analyze a cohort of

3500 unrelated NF1 patients for gross NF1 deletions. A total of 146 individuals (4.2\%) were

identified as harbouring gross NF1 deletions. Of these 146 NF1 deletions, 116 were type-1, 16

were type-2, two were type-3 and 12 were atypical (Table 1). Somatic mosaicism was

identified in $14(10 \%)$ of the 146 patients with $N F 1$ deletions including 4 individuals with

putative type-1 NF1 deletions (Table 1), as suggested by MLPA performed with DNA from

whole blood samples (patients UAB-r3302, UAB-r7332 and UAB-r3222) or with DNA

derived from café-au-lait spot melanocytes (patient UAB-M1). Wjth the currently available

Deleted: However,

Deleted: w

MLPA-kit, it is however impossible to distinguish type-1 NF1 deletions (with breakpoints in

the NF1-REPs) from atypical deletions with breakpoints located close to the NF1-REPs A and

C. Consequently, further analyses were needed in order to narrow down the extent of the

Deleted: i

deletions in these 4 patients, as outlined in the following paragraphs.

Deleted: extent

In patient UAB-M1, comprehensive NF1 mutation analysis revealed a splice site mutation

(c.889-2A $>\mathrm{G}$ ) at the splice acceptor site of exon 7 (according to the traditional exon

nomenclature ${ }_{2}$ or exon 9 according to the numbering from sequence NM_000267.3) in

addition to a type-1 NF1 deletion in melanocyte-derived DNA from this patient. The presence

of two hits in the café-au-lait spot melanocytes of this patient is in line with our previous

findings [Maertens et al., 2007; De Schepper et al., 2008]. Remarkably, neither the NF1

deletion nor the splice site mutation were identifiable in DNA from café-au-lait spot-derived

Deleted: 
fibroblast cell cultures from patient UAB-M1. Unfortunately, neither a blood sample nor a biopsy from a second café-au-lait spot from this patient was available. Thus, it remains. unclear whether or not the NFI deletion represented the first-hit mutation in this patient. Mosaicism in patients UAB-r3302, UAB-r7332 and UAB-r3222, from whom blood samples were available, was ascertained by interphase FISH as summarized in Table 2.

Since the currently available MLPA-kit does not allow an unambiguous distinction to be made between type-1 NF1 deletions and atypical deletions characterized by breakpoints located close to the NF1-REPs (Figure 1A), it could not be formally confirmed that the 4 putative mosaic deletions (detected in patients UAB-M1, UAB-r3302, UAB-r7332 and UABr3222) were indeed type-1. To characterize the extent of these deletions, we performed breakpoint-spanning PCRs or SNP analysis as outlined below.

\section{Breakpoint identification by PCR}

Employing breakpoint-spanning PCR, we next investigated whether the breakpoints of the deletions in patients UAB-r3302, UAB-r3222 and UAB-r7332 were located within the PRS1 and PRS2 hotspots. In patient UAB-r3222, a PRS2 breakpoint-spanning fragment was obtained and subsequent sequence analysis confirmed that the deletion breakpoint was indeed located within the PRS2 hotspot. However, patients UAB-r3302 and UAB-r7332 were both negative by breakpoint-spanning PCR analysis for PRS1 and PRS2. Therefore, we investigated whether the deletion breakpoints in these two patients might be located in the same genomic region within which the deletion breakpoint of patient UWA160-1 had been previously identified [Forbes et al., 2004]. These authors mapped the deletion breakpoints of patient UWA160-1 some 23-kb centromeric to the PRS1 region (Supp Figure S2). However, PCR assays with primers designed to amplify across these deletion breakpoints (those noted in patient UWA160-1) were negative in both patients UAB-r3302 and UAB-r7332. 
Breakpoint-spanning PCR assays could not be performed with DNA isolated from melanocyte cultures of patient UAB-M1 on account of the paucity of the DNA obtained.

Deletion junction PCRs were also performed to analyse DNA samples from patient P067.

Previously performed microsatellite marker analysis had indicated loss of heterozygosity (LOH) in DNA isolated from a neurofibroma from patient P067 (tumour P067-2N) as described by Garcia-Linares et al., [2010]. MLPA analysis of NF1 -/- Schwann cells from this tumour was suggestive of the presence of a type-1 NF1 deletion [Garcia-Linares et al., 2010]. In this study, we investigated whether the deletion breakpoints were located within the PRS1 and PRS2 regions. A PRS1-spanning PCR product was successfully amplified from DNA of neurofibroma P067-2N. Surprisingly, another neurofibroma (tumour P067-1N) from this patient also proved positive in the PRS1 deletion junction assay even although LOH was not detected in this tumour. Additionally, the PRS1 breakpoint-spanning fragment was detected in DNA samples isolated from the skin overlying both neurofibromas. These findings strongly implied that patient $\mathrm{P} 067$ is mosaic for a type-1 NF1 deletion and that the deletion is not tumour-specific but rather occurred during embryonic development resulting in somatic mosaicism. Remarkably, the PRS1 breakpoint-spanning PCR was not positive using DNA isolated from blood and saliva containing up to 74\% leucocytes [Thiede et al., 2000]. Thus, the type-1 NF1 deletion is either absent from the blood cells of patient P067 or alternatively occurs at a level that is below the detection limit of the breakpoint-spanning PCR assays. We therefore concluded that patient P067, who manifests segmental NF1, is mosaic for a type-1 deletion that is probably confined to specific cell lineages.

\section{SNP analysis}

Since patients UAB-r3302 and UAB-r7332 were negative for the breakpoint-spanning PCRs designed to detect NAHR events within the PRS1 and PRS2 hotspots, it was unclear whether the respective deletion breakpoints were located within NF1-REPs A and C, as is 
characteristic of type-1 NF1 deletions. To determine the extent of these deletions and that of

patient UAB-M1, we performed SNP analysis ( $\mathrm{Supp}_{\sharp}$ Table S2). Heterozygosity for SNPs located between the MLPA probes and the NF1-REPs would indicate that the region tagged by these SNPs is not deleted. However, this method is not without its limitations, i.e. the availability of heterozygous (and hence informative) SNPs. Further, the majority of SNPs assigned to the NF1-REPs by the HapMap Genome Browser are not well genotyped and hence could represent paralogous sequence variants rather than SNPs. Despite these limitations, the SNP analysis indicated the presence of a heterozygous type-1 deletion in patient UAB-r3302. Since heterozygosity for SNPs rs216440 and rs7218060 was observed, we conclude that the deletion breakpoints in patient UAB-r3302 are probably, located within NF1-REPs A and C (Figure 1B). By contrast, the centromeric deletion breakpoint in patient UAB-r7332 could not be unequivocally assigned to within NF1-REP A, since the distance between the heterozygous SNP rs216455 and the centromeric boundary of NF1-REP A was found to be $\sim 37-\mathrm{kb}$ (Figure $1 \mathrm{C}$ ). In patient UAB-M1, the extent of the deletion could not be narrowed down any further by SNP analysis. Hence, a type-1 NF1 deletion could not be unequivocally demonstrated in either patient UAB-M1 or UAB-r7332.

\section{Discussion}

The type-1 NF1 deletion is the most frequently encountered type of NF1 microdeletion. Indeed, previous studies have suggested that $\sim 80 \%$ of all $N F 1$ deletions are type-1 [Dorschner et al., 2000; Forbes et al., 2004; Pasmant et al., 2010]. The results of the analysis presented here, the largest performed to date, provides independent confirmation of this estimate since 116 of the 146 NF1 deletions identified by MLPA were deemed likely to be type-1 (79\%; Table 1). Only 16 of these 116 cases with type- 1 deletions were familial, the rest occurred $d e$ novo. FISH analysis indicated that 4 of these 116 type- 1 deletions were mosaic cases.

However, some doubt remained as to the deletion type since MLPA is not well suited to 
distinguish unequivocally between type-1 deletions and atypical deletions with breakpoints located outside of (but close to) the NF1-REPs (Figure 1A). Therefore, we reanalysed these 4 putative mosaic type-1 deletions using methods capable of providing a higher level of resolution of the breakpoint positions than MLPA. By these means, we were able to confirm that two of these four deletions, those harboured by patients UAB-r3222 and UAB-r3302, were indeed type-1. Thus, at least $2 \%$ (up to $4 \%$ ) of all patients with de novo type-1 NF1 deletions exhibit mosaicism.

In the cohort of $146 \mathrm{NF} 1$ deletions investigated here, 16 type-2 deletions were detected.

Ten of these 16 patients with type- 2 deletions were known sporadic cases, whereas three, Deleted: 3 patients with type-2 deletions were familial. For a further three, cases, it was unknown Deleted: 3 whether they were sporadic or familial. Remarkably, 7 of the 10 known sporadic patients with type-2 deletions exhibited mosaicism with normal cells $(70 \%)$ and all seven patients were females. This supports previous findings of a preponderance of females among patients with type-2 NF1 deletions [Steinmann et al., 2007]. The actual proportion of mosaic type-2 deletions within this cohort could however have been underestimated since the parents of the non-founder type-2 deletion patients were not investigated by FISH. Thus, mosaicism in the founders of such families could not be unequivocally excluded. Indeed, in a previous analysis, we observed three cases of the transmission of a type-2 NF1 deletion from a mosaic parent, exhibiting no (or only minor) disease manifestations, to a child [Steinmann et al., 2007]. Furthermore, 16 of 18 patients with type- $2 N F 1$ deletions investigated previously exhibited somatic mosaicism [Roehl et al., 2010b]. These studies also indicated that in the majority of patients with type- 2 deletions, the proportion of cells bearing the deletion is very high (>90\%) in blood but considerably lower in buccal smears. Importantly, although such deletions will have been identified using aCGH or MLPA analysis, these techniques would have been inadequate to the task of identifying their mosaic nature, especially when the fraction of nondeleted alleles was low. Hence the use of FISH analysis, on blood or other cell types (e.g. 
from buccal smears, urine samples etc), is advisable as an additional detection technique in potential cases of mosaicism.

Even if we underestimated the frequency of mosaic type-2 deletions in this study, the analysis of the $146 \mathrm{NFI}$ deletions served to indicate that somatic mosaicism occurs much more frequently in association with type-2 deletions than with type-1 deletions (cf. at least $70 \%$ vs. $2 \%$ ). We have proposed that the relative frequencies of meiotic vs. mitotic (postzygotic) NAHR events within the $N F 1$ gene region are likely to correlate with specific sequence features at the breakpoints which necessarily differ between the two deletion types. These features could include GC-content as well as the presence of recombination-promoting sequence motifs [Roehl et al., 2010b and references therein].

In addition to the confirmed mosaic type- $1 N F 1$ deletions observed in patients UAB-r3222 and UAB-r3302 from the cohort of 146 deletion patients, we identified a third case of a mosaic type-1 NFI deletion in patient $\mathrm{P} 067$, who was initially investigated during the course of an LOH study in neurofibromas [Garcia-Linares et al., 2010]. The mosaic type-1 deletion in this patient was observed in two different neurofibromas and overlying skin samples only

after breakpoint identification by PCR. Taken together, these three cases represent the first examples of mosaic type-1 deletions that have been unequivocally confirmed by high resolution techniques. Two of the three mosaic type-1 deletions, those identified in patients P067 and UAB-r3222, had breakpoints within the PRS1 and PRS2 regions, respectively. Previous studies have shown that $70-80 \%$ of all germline type- 1 NF1 deletions exhibit breakpoints within these hotspots of NAHR [Lopéz-Correa et al., 2001; Forbes et al., 2004]. Since the majority of germline type-1 NFI deletions occur during maternal meiosis I [LopézCorrea et al., 2000], PRS1 and PRS2 have long been considered to represent NAHR hotspots that were specific to maternal meiosis. However, our discovery that the breakpoints of mosaic type-1 deletions may sometimes also be located in PRS1 and PRS2 indicates that NAHR is not confined exclusively to maternal meiosis but may also occur within these recombination 
hotspots during postzygotic (mitotic) cell cycles even although the frequency of occurrence of NAHR is much lower than during meiosis,

\section{We have previously proposed that a high frequency of mosaicism observed in several} cancer predisposition syndromes may be related to a high new mutation rate $[$ Kehrer-

Sawatzki and Cooper, 2008]. Our current analysis demonstrates that mosaicism represents an important consideration in the analysis and diagnosis of all types of gross NFI deletion (Table

1). Mosaicism in NF1 can be associated either with a generalized but often mild disease manifestation or alternatively a regionally limited distribution of NF1 disease features, termed segmental NF1 [Ruggieri and Huson, 2001]. Estimates of the prevalence of segmental NF1 in the general population range from $0.0006 \%$ [Wolkenstein et al., 1995] to $0.0018 \%$ [Ingordo et al., 1995]. Although unusual, many patients with this condition have been described in the literature [Ruggieri, 2001; Ruggieri and Huson, 2001; Listernick et al., 2003 and references therein; Redlick and Shaw, 2004]. So far, mutations have only been reported in 5 cases of segmental NF1, three of these carrying atypical NF1 deletions (Supp Table S3) [Tinschert et al., 2000; Consoli et al., 2005; Maertens et al., 2007]. Remarkably, patient P067 identified in this study is the first individual described who not only has a mosaic type- 1 NF1 deletion but also segmental NF1. The breakpoints of this patient's somatic deletion are both located within PRS1, a recombination hotspot previously shown to harbour breakpoints of germline type-1 NF1 deletions [Forbes et al., 2004; De Raedt et al., 2006]. We may however infer that the NAHR event responsible for the deletion jn patient P067 must have occurred relatively late on during embryonic development, giving rise to the highly localized manifestation of the disease (Supp Figure S1). Importantly, the type-1 deletion was detected only in tumour samples and skin samples overlying the tumours from patient P067 but not in either her blood or saliva. Similarly, Consoli et al., [2005] described a patient with segmental NF1 and a mosaic R1947X NF1 gene mutation that was only detectable in keratinocyte and fibroblast
Deleted: We have previously proposed that the high new mutation rate in several cancer predisposition syndromes may be related to a high frequency of mosaicism
Deleted: lementary 
cell lines isolated from a café-au-lait spot but not in unaffected skin samples or peripheral blood of the patient.

By contrast, the remaining two patients shown to harbour a mosaic type-1 NF1 deletion (UAB-r3222 and UAB-r3302) exhibited a generalized manifestation of the disease. Many of the mosaic NF1 cases identified to date have been associated with a generalized (albeit mild) disease manifestation, but without typical symptoms being restricted to only a few regions of the body [Ruggieri and Huson, 2001; reviewed in Kehrer-Sawatzki and Cooper, 2008; Bottillo et al., 2010; Kaplan et al., 2010; Muram-Zborovski et al., 2010]. From the clinical point of view, it is very difficult to distinguish mosaic NF1 patients with generalized manifestations from those classical patients with germline NF1 mutations. Phenotypically, patients UAB-r3222 and UAB-r3302 gave no outward and visible clue that their type-1 deletions might be mosaic. This implies that a comprehensive NF1 screening protocol, which should also include FISH analysis, will be necessary to assess mosaicism in all types of gross NF1 deletion.

Acknowledgements

This work was supported by the Deutsche Forschungsgemeinschaft [DFG grants KE 724/9-1;

KE 724/7-1; H. K.-S.], by the Deutsche Krebshilfe (grant \#108793, H.K.-S.) and from the Spanish Health Research Fund, the Carlos III Health Institute, the Catalan Health Institute and Autonomous Government of Catalonia, the Asociación Española de Afectados de Neurofibromatosis and the Asociación Española contra el Cáncer (ISCIIIRETIC:

RD06/0020/1051 and RD06/0020/1050, PI081871 and 2009SGR290). J. V. holds a fellowship from the International Graduate School in Molecular Medicine, Ulm.

\section{References}


Bengesser K, Cooper DN, Steinmann K, Kluwe L, Chuzhanova NA, Wimmer K, Tatagiba M, Tinschert S, Mautner VF, Kehrer-Sawatzki H. 2010. A novel third type of recurrent NF1 microdeletion mediated by non-allelic homologous recombination between LRRC37Bcontaining low-copy repeats in 17q11.2. Hum Mutat 31:742-751.

Bottillo I, Torrente I, Lanari V, Pinna V, Giustini S, Divona L, De Luca A, Dallapiccola B. 2010. Germline mosaicism in neurofibromatosis type 1 due to a paternally derived multi-exon deletion. Am J Med Genet A 152A:1467-1473.

Consoli C, Moss C, Green S, Balderson D, Cooper DN, Upadhyaya M. 2005. Gonosomal mosaicism for a nonsense mutation (R1947X) in the NF1 gene in segmental neurofibromatosis type 1. J Invest Dermatol 125:463-466.

De Luca A, Bottillo I, Dasdia MC, Morella A, Lanari V, Bernardini L, Divona L, Giustini S, Sinibaldi L, Novelli A, Torrente I, Schirinzi A, Dallapiccola B. 2007. Deletions of NF1 gene and exons detected by multiplex ligation-dependent probe amplification. J Med Genet 44:800808.

De Raedt T, Brems H, Lopez-Correa C, Vermeesch JR, Marynen P, Legius E. 2004. Genomic organization and evolution of the NF1 microdeletion region. Genomics 84:346-360.

De Raedt T, Stephens M, Heyns I, Brems H, Thijs D, Messiaen L, Stephens K, Lazaro C, Wimmer K, Kehrer-Sawatzki H, Vidaud D, Kluwe L, Marynen P, Legius E. 2006. Conservation of hotspots for recombination in low-copy repeats associated with the NF1 microdeletion. Nat Genet 38:1419-1423. 
De Schepper S, Maertens O, Callens T, Naeyaert JM, Lambert J, Messiaen L. 2008 Somatic mutation analysis in NF1 café au lait spots reveals two NF1 hits in the melanocytes. J Invest Dermatol 128:1050-3.

Dorschner MO, Sybert VP, Weaver M, Pletcher BA, Stephens K. 2000. NF1 microdeletion breakpoints are clustered at flanking repetitive sequences. Hum Mol Genet 9:35-46.

Erickson RP. 2010. Somatic gene mutation and human disease other than cancer: An update. Mutat Res 705:96-106.

Friedman JM, Gutmann DH, MacCollin M, Riccardi VM. 1999. Clinical and epidemiological features. Friedman JM, Riccard VM, eds. Neurofibromatosis: Phenotype, Natural History and Pathogenesis. 3rd edn. Baltimore: Johns Hopkins University Press. pp29-86.

Forbes SH, Dorschner MO, Le R, Stephens K. 2004. Genomic context of paralogous recombination hotspots mediating recurrent NF1 region microdeletion. Genes Chrom Cancer 41:12-25.

Garcia-Linares C, Fernández-Rodríguez J, Terribas E, Mercadé J, Pros E, Benito L, Benavente Y, Capella G, Ravella A, Blanco I, Kehrer-Sawatzki H, Lázaro C, Serra E. 2010. Dissecting loss of heterozygosity $(\mathrm{LOH})$ in neurofibromatosis type 1-associated neurofibromas: importance of copy neutral LOH. Hum Mutat, in press

Gottlieb B, Beitel LK, Trifiro MA. 2001. Somatic mosaicism and variable expressivity. Trends Genet 17:79-82. 
Ingordo V, D'Andria G, Mendicini S, Grecucci M, Baglivo A. 1995. Segmental neurofibromatosis: is it uncommon or underdiagnosed? Arch Dermatol. 131:959-960.

Jenne DE, Tinschert S, Reimann H, Lasinger W, Thiel G, Hameister H, Kehrer-Sawatzki H. 2001. Molecular characterization and gene content of breakpoint boundaries in patients with neurofibromatosis type 1 with 17q11.2 microdeletions. Am J Hum Genet 69:516-527.

Kaplan L, Foster R, Shen Y, Parry DM, McMaster ML, O'Leary MC, Gusella JF. 2010. Monozygotic twins discordant for neurofibromatosis 1. Am J Med Genet A 152A:601-606.

Kehrer-Sawatzki H, Cooper DN. 2008. Mosaicism in sporadic neurofibromatosis type 1: variations on a theme common to other hereditary cancer syndromes? J Med Genet 45:622631.

Kehrer-Sawatzki H, Kluwe L, Sandig C, Kohn M, Wimmer K, Krammer U, Peyrl A, Jenne DE, Hansmann I, Mautner VF. 2004. High frequency of mosaicism among patients with neurofibromatosis type 1 (NF1) with microdeletions caused by somatic recombination of the JJAZ1 gene. Am J Hum Genet 75:410-423.

Kehrer-Sawatzki H, Schmid E, Fünsterer C, Kluwe L, Mautner VF. 2008. Absence of cutaneous neurofibromas in an NF1 patient with an atypical deletion partially overlapping the common 1.4 Mb microdeleted region. Am J Med Genet A 146A:691-699.

Kluwe L, Siebert R, Gesk S, Friedrich RE, Tinschert S, Kehrer-Sawatzki H, Mautner VF. 2004. Screening 500 unselected neurofibromatosis 1 patients for deletions of the NF1 gene. Hum Mutat 23:111-116. 
Lammert M, Friedman JM, Kluwe L, Mautner VF. 2005. Prevalence of neurofibromatosis 1 in German children at elementary school enrollment. Arch Dermatol 141:71-74.

Listernick R, Mancini AJ, Charrow J. 2003. Segmental neurofibromatosis in childhood. Am J Med Genet A 21A:132-135.

López-Correa C, Brems H, Lázaro C, Marynen P, Legius E. 2000. Unequal meiotic crossover: a frequent cause of NF1 microdeletions. Am J Hum Genet 66:1969-1974.

López-Correa C, Dorschner M, Brems H, Lázaro C, Clementi M, Upadhyaya M, Dooijes D, Moog U, Kehrer-Sawatzki H, Rutkowski JL, Fryns JP, Marynen P, Stephens K, Legius E. 2001. Recombination hotspot in NF1 microdeletion patients. Hum Mol Genet 10:1387-1392.

Maertens O, De Schepper S, Vandesompele J, Brems H, Heyns I, Janssens S, Speleman F, Legius E, Messiaen L. 2007. Molecular dissection of isolated disease features in mosaic neurofibromatosis type 1. Am J Hum Genet 81:243-251.

Messiaen L, Wimmer K. 2008. NF1 mutational spectrum. In Monogr Hum Genet, Kaufmann D. (ed): Neurofibromatoses, Basel, Karger vol.16, pp 63-77.

Muram-Zborovski TM, Vaughn CP, Viskochil DH, Hanson H, Mao R, Stevenson DA. 2010. NF1 exon 22 analysis of individuals with the clinical diagnosis of neurofibromatosis type 1. Am J Med Genet A 152A:1973-1978. 
Mautner VF, Kluwe L, Friedrich RE, Roehl AC, Bammert S, Högel J, Spöri H, Cooper DN, Kehrer-Sawatzki H. 2010. Clinical characterisation of 29 neurofibromatosis type-1 patients with molecularly ascertained 1.4 Mb type-1 NF1 deletions. J Med Genet 47:623-630.

Mensink KA, Ketterling RP, Flynn HC, Knudson RA, Lindor NM, Heese BA, Spinner RJ, Babovic-Vuksanovic D. 2006. Connective tissue dysplasia in five new patients with NF1 microdeletions: further expansion of phenotype and review of the literature. J Med Genet 43:e8.

Pasmant E, de Saint-Trivier A, Laurendeau I, Dieux-Coeslier A, Parfait B, Vidaud M, Vidaud $\mathrm{D}$, Bièche I. 2008. Characterization of a 7.6-Mb germline deletion encompassing the NFI locus and about a hundred genes in an NF1 contiguous gene syndrome patient. Eur J Hum Genet 16:1459-1466.

Pasmant E, Sabbagh A, Spurlock G, Laurendeau I, Grillo E, Hamel MJ, Martin L, Barbarot S, Leheup B, Rodriguez D, Lacombe D, Dollfus H, Pasquier L, Isidor B, Ferkal S, Soulier J, Sanson M, Dieux-Coeslier A, Bièche I, Parfait B, Vidaud M, Wolkenstein P, Upadhyaya M, Vidaud D; members of the NF France Network. 2010. NF1 microdeletions in neurofibromatosis type 1: from genotype to phenotype. Hum Mutat 31:E1506-1518.

Redlick FP, Shaw JC. 2004. Segmental neurofibromatosis follows Blaschko's lines or Deleted: b dermatomes depending on the cell line affected: case report and literature review. J Cutan Med Surg 8:353-356. 
Roehl AC, Cooper DN, Kluwe L, Helbrich A, Wimmer K, Högel J, Mautner VF, KehrerSawatzki H. 2010a. Extended runs of homozygosity at 17q11.2: an association with type-2 NF1 deletions? Hum Mutat 31:325-334.

Roehl AC, Vogt J, Mussotter T, Zickler AN, Spöri H, Högel J, Chuzhanova NA, Wimmer K, Kluwe L, Mautner VF, Cooper DN, Kehrer-Sawatzki H. 2010b. Intrachromosomal mitotic nonallelic homologous recombination is the major molecular mechanism underlying type-2

Ruggieri M, Huson SM. 2001. The clinical and diagnostic implications of mosaicism in the neurofibromatoses. Neurology 56:1433-1443.

Steinmann K, Cooper DN, Kluwe L, Chuzhanova NA, Senger C, Serra E, Lázaro C, Gilaberte M, Wimmer K, Mautner VF, Kehrer-Sawatzki H. 2007. Type 2 NF1 deletions are highly unusual by virtue of the absence of nonallelic homologous recombination hotspots and an apparent preference for female mitotic recombination. Am J Hum Genet 81:1201-1220.

Thiede C, Prange-Krex G, Freiberg-Richter J, Bornhäuser M, Ehninger G. 2000. Buccal swabs but not mouthwash samples can be used to obtain pretransplant DNA fingerprints from recipients of allogenic bone marrow transplants. Bone Marrow Transplant 25:575-577. 
Tinschert S, Naumann I, Stegmann E, Buske A, Kaufmann D, Thiel G, Jenne DE. 2000.

Segmental neurofibromatosis is caused by somatic mutation of the neurofibromatosis type 1 (NF1) gene. Eur J Hum Genet 8:455-459.

Wimmer K, Yao S, Claes K, Kehrer-Sawatzki H, Tinschert S, De Raedt T, Legius E, Callens T, Beiglböck H, Maertens O, Messiaen L. 2006. Spectrum of single- and multiexon NF1 copy number changes in a cohort of 1,100 unselected NF1 patients. Genes Chrom Cancer 45:265276.

Wolkenstein P, Mahmoudi A, Zeller J, Revuz J. 1995. More on the frequency of segmental neurofibromatosis. Arch Dermatol 131:1465.

Venturin M, Guarnieri P, Natacci F, Stabile M, Tenconi R, Clementi M, Hernandez C, Thompson P, Upadhyaya M, Larizza L, Riva P. 2004. Mental retardation and cardiovascular malformations in NF1 microdeleted patients point to candidate genes in 17q11.2. J Med Genet 41:35-41.

Youssoufian H, Pyeritz RE. 2002. Mechanisms and consequences of somatic mosaicism in humans. Nat Rev Genet 3:748-758. 


\section{Legend}

Figure 1: Schema of the $N F 1$ gene region indicating the genes located therein, the relative positions of the MLPA probes employed and the SNPs investigated in the characterization of the extent of the gross NF1 deletions in patients UAB-r3302 and UAB-r7332. (A) The functional genes located within the $N F 1$ microdeletion region at $17 \mathrm{q} 11.2$ are indicated by black bars. LRRC37B2 and SUZ12P are pseudogenes. The positions of the MLPAprobes deleted in the case of type-1 NF1 deletions are given by grey arrows, whereas those not deleted are denoted by black arrows. The name and genomic position of each MLPA probe are as follows: arrow no. 1: MLPA probe CPD 9628-L9913 (25,795038); no. 2: CPD 9629L9914 (25,813,548); no. 3: SUZ12p before ex1 11798-L12590 (26,082,519); no. 4: SUZ12p ex1 11801-L12591 (26,082,967); no. 5: SUZ12p ex6 11801-L12592 (26,109,273); no. 6: CRLF3 3780-L3290 (26,148,508); no. 7: ATAD5 3781-L3290 (26,186,172); no.8: CENTA2 3782-L3291 (26,278,001); no. 9: RNF135 3783-L3292 (26,335,816); no. 10: NF1 Ex. 12491 L1922 (26,445,726); no. 11: NF1 Ex. 12B 2507-L1938 (26,576,330); no. 12: NF1 Ex. 23-2 2512-L1943 (26,600,151); no. 13: NF1 Ex. 40 2525-L1943 (26,700,280); no. 14: NF1 Ex. 48 5220-L3309 (26,711,704); no. 15: UTP6 3785-L3294 (27,226,463); no. 16: JJAZ1 3786L3295 (27,339,525); no. 17: LRRC37B 3787-L3296 (27,372,684); no. 18: ZNF207 9637L9949 (27,717,868). (B) Positions of the heterozygous SNPs (rs216440 and rs7218060) in patient UAB-r3302 relative to NF1-REP A and NF1-REP C. Numbers indicate the nucleotide positions of SNPs, MLPA probes and the extent of NF1-REPs A and C according to the sequence of the Human Genome Assembly, 18 March 2006, NCBI Build 36.1. The MLPA Deleted: probes within $S U Z 12 P$ and $L R R C 37 B$, located within the deletion region, are identified by red arrows, whereas those MLPA probes not deleted are denoted by black arrows. SNP rs216440, Deleted: located at nucleotide position 25,952,435, is located within NF1-REP A, which begins at position 25,951,642. Heterozygosity for this SNP was observed in patient UAB-r3302. The telomeric end of NF1-REP A (at 26,079,631) is separated from the MLPA probe within SUZ12P (at 26,082,519) by $\sim 2.8-\mathrm{kb}$. The distance between SNP rs7218060 and the telomeric end of NF1-REP C is $\sim 3.9-\mathrm{kb}$. (C) Positions of heterozygous SNPs (rs216455 and rs7218060) in patient UAB-r7332 relative to NF1-REP A and NF1-REP C. The distance between SNP rs216455 (at nucleotide position 25,914,329) and the centromeric boundary of NF1-REP A is $\sim 37$-kb. The distance between SNP rs7218060 and the telomeric end of NF1-REP C is 3.9$\mathrm{kb}$. 
Table 1: Frequency of type-1, type-2, type-3 and atypical NF1 deletions among the 146 deletions identified by MLPA in a cohort of 3500 NF1 patients

\begin{tabular}{l|ccccc}
\hline & \multicolumn{4}{|c}{ NF1 deletion } & Total \\
& type-1 & type-2 & type-3 & atypical & \\
\hline $\begin{array}{l}\text { Number of deletions with } \\
\text { this type among the total of } \\
146 \text { NF1 deletions }\end{array}$ & $116(79.4 \%)$ & $16(11 \%)$ & $2(1.4 \%)$ & $12(8.2 \%)$ & 146 \\
\hline $\begin{array}{l}\text { Frequency of deletion of a } \\
\text { given type among all 3500 } \\
\text { NF1 patient investigated }\end{array}$ & $3.3 \%$ & $0.5 \%$ & $0.01 \%$ & $0.3 \%$ & - \\
\hline $\begin{array}{l}\text { Number of mosaic cases } \\
\text { with the given deletion type }\end{array}$ & $4^{\mathrm{a}}$ & 7 & 0 & 3 & 14 \\
\hline
\end{tabular}

a: Two of these 4 putative type-1 NFI deletions were confirmed as such by means of breakpoint-spanning PCR and SNP analysis. 
A

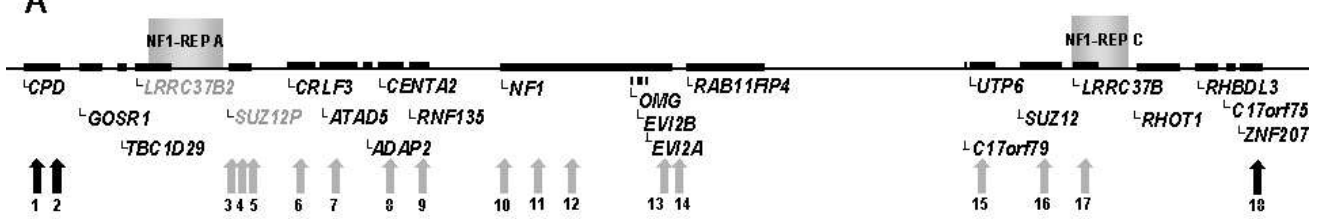

B

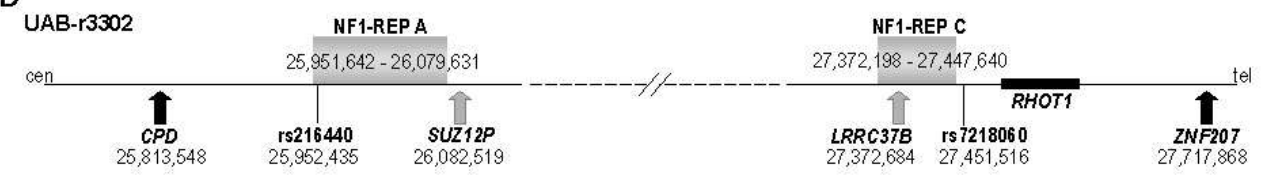

C

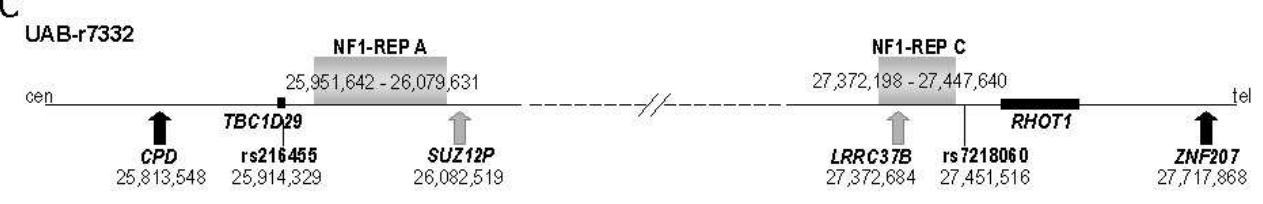

Figure 1

$81 \times 60 \mathrm{~mm}(300 \times 300$ DPI $)$

John Wiley \& Sons, Inc. 

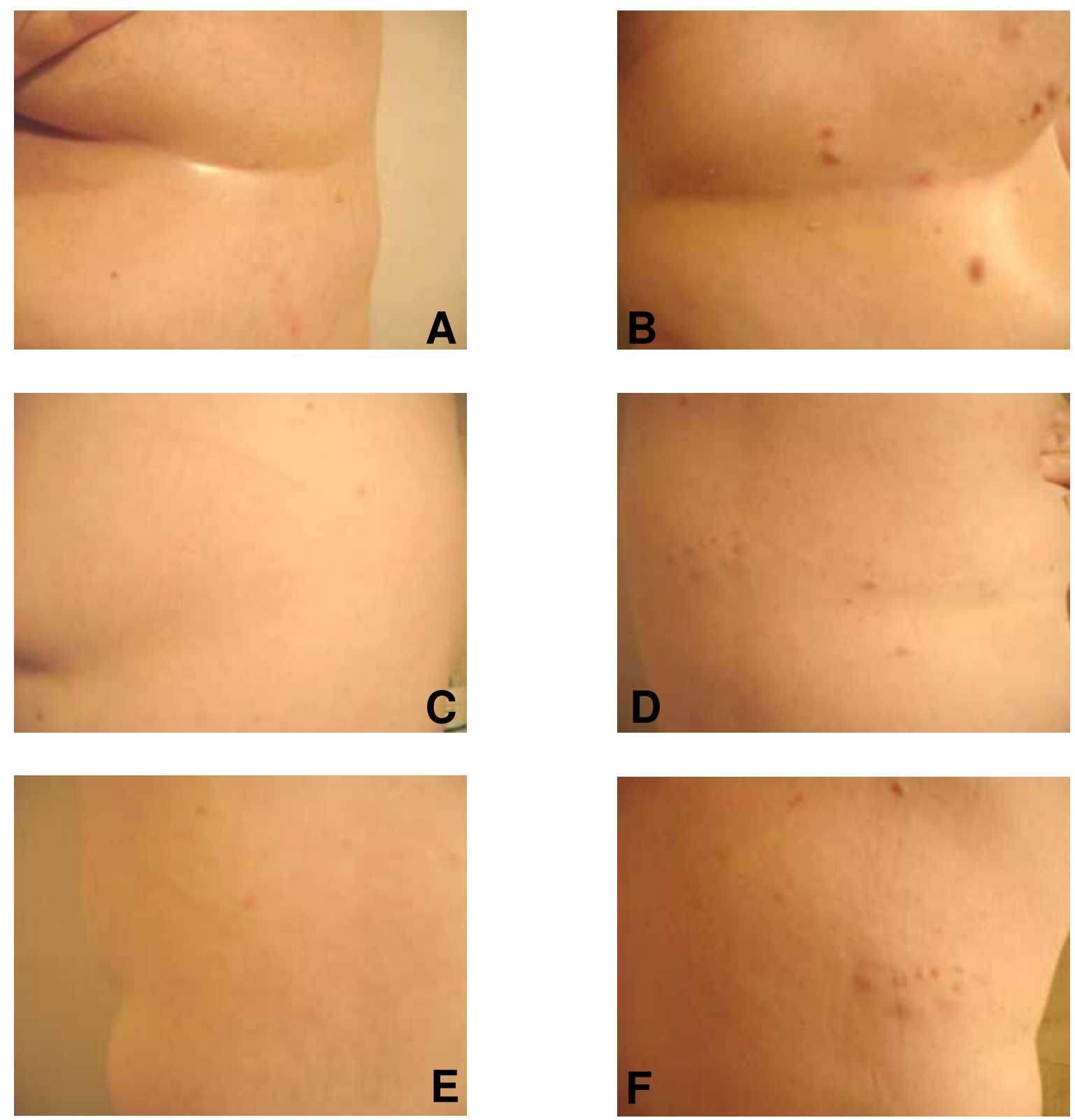

Supplementary Figure S1: Segmental NF1 in patient P067. The patient manifested disease features (small neurofibromas and freckling) which were confined to the region below the right breast (B), on the right upper flank (D) and back (F). In A, C and E, the corresponding unaffected regions on the left side are depicted. 


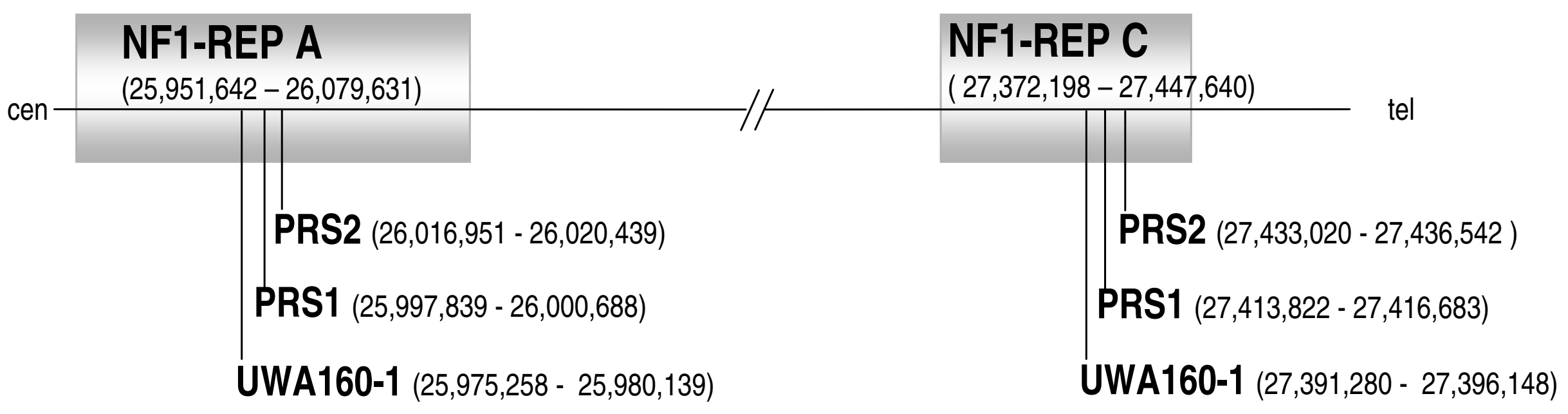

Supplementary Figure S2: Schematic diagram of the genomic region of the NF1-REPs and the relative positions of the deletion breakpoint hotspot regions PRS1 and PRS2. The deletion breakpoint region of patient UWA160-1, identified previously by Forbes et al., [2004], is also indicated. The numbers in parentheses refer to genomic positions according to the base-pair numbering of chromosome 17 in the Human Genome Assembly, 18 March 2006, NCBI Build 36.1, database version 44.36f. 
Supplementary Table S1: Primers used for breakpoint-spanning PCRs to amplify type-1 NF1 deletion breakpoints located within the paralogous recombination sites 1 and 2 (PRS1 and PRS2) according to Lopéz-Correa et al., [2001] and Forbes et al., [2004]

\begin{tabular}{|l|l|l|l|l|}
\hline Primer & Sequence 5' $\rightarrow \mathbf{3}^{\prime}$ & $\begin{array}{l}\text { Size of } \\
\text { PCR } \\
\text { product }\end{array}$ & $\begin{array}{l}\text { Position on } \\
\text { chromosome 17 }\end{array}$ & $\begin{array}{l}\text { Paralogous } \\
\text { recombination site } \\
\text { detected within the } \\
\text { NF1-REPs }\end{array}$ \\
\hline $\begin{array}{l}\text { DJ2290 } \\
\text { DJ2290r }\end{array}$ & $\begin{array}{l}\text { TCAACCTCCCAGGCTCCCGAA } \\
\text { AGCCCCGAGGGGATGAAAAGC }\end{array}$ & $3.5-\mathrm{kb}$ & $\begin{array}{l}26,016,951-26,016,971 \\
27,436,522-27,436,542\end{array}$ & PRS2 \\
ext-f & CAACCTCCCAGGCTCAAGTG & $7-\mathrm{kb}$ & $26,016,952-26,016,971$ & \\
ext-r & GGCAGGGTTAGGAGCTCTGGAA & $27,440,231-27,440,252$ & \\
\hline $\begin{array}{l}\text { md4f } \\
\text { m30r }\end{array}$ & ATCCTGTAGCCCAGTTCTCCTC & $2.9-\mathrm{kb}$ & $25,997,839-25,997,860$ & PRS1 \\
& CAGTGAACCGAGATTGTACTACCA & & $27,416,683-27,416,706$ & \\
\hline
\end{tabular}

a : According to the nucleotide numbering in the Human Genome Assembly, 18 March 2006, NCBI Build 36.1, database version 44.36f. 
Supplementary Table S2: SNP analysis in NF1 patients UAB-r3302, UAB-r7332, and UAB-M1 who were negative for the PCRs designed to detect deletion breakpoints in the paralogous recombination sites PRS1 and PRS2

\begin{tabular}{|c|c|c|c|c|c|c|c|}
\hline \multirow{2}{*}{\begin{tabular}{|l|} 
PCR- \\
Primer
\end{tabular}} & \multirow[t]{2}{*}{ SNP } & \multirow[t]{2}{*}{ SNP position ${ }^{\mathrm{a}}$} & \multirow{2}{*}{$\begin{array}{l}\text { Heterozygosity } \\
\text { frequency in CEUs }\end{array}$} & \multirow{2}{*}{$\begin{array}{l}\text { Primer sequence } \\
5^{\prime} \rightarrow 3,\end{array}$} & \multicolumn{3}{|c|}{ Alleles detected in patient ${ }^{b}$} \\
\hline & & & & & UAB-r3302 & UAB-r7332 & UAB-M1 \\
\hline $45 \mathrm{f} / 46 \mathrm{r}$ & rs216466 & $25,884,080$ & $\mathrm{C} / \mathrm{T} 0.504$ & \begin{tabular}{|l} 
AGATGCATGGAGTTCGAAGAG \\
AGCCTGCACAGGTCACTTTT
\end{tabular} & $\mathrm{C} / \mathrm{T}$ & $\mathrm{C} / \mathrm{T}$ & - \\
\hline $55 \mathrm{f} / 56 \mathrm{r}$ & rs216455 & $25,914,329$ & $\mathrm{C} / \mathrm{T} 0.400$ & $\begin{array}{l}\text { GGAACCCCATCCCTACTACC } \\
\text { GCTCAAGGCTTGTTGTCCTG }\end{array}$ & $\mathrm{T} / \mathrm{C}$ & $\mathrm{T} / \mathrm{C}$ & - \\
\hline $1 f / 2 r$ & rs 170053 & $25,917,209$ & $\mathrm{C} / \mathrm{T} 0.491$ & \begin{tabular}{|l} 
AGAGTCCCTGGGGGAGAAC \\
GGTTTCCCGAGACTCACACA \\
\end{tabular} & n.d. & $\mathrm{T}$ & n.d. \\
\hline $29 \mathrm{f} / 30 \mathrm{r}$ & rs216462 & $25,920,023$ & $\mathrm{C} / \mathrm{T} 0.212$ & \begin{tabular}{|l} 
CGCAGCTTGCTGAGGAGT \\
AGGGTCAGACAGAGCAGAGG \\
\end{tabular} & n.d. & $\mathrm{C}$ & n.d. \\
\hline $7 \mathrm{f} / 8 \mathrm{r}$ & rs17606460 & $25,923,150$ & C/T 0.416 & $\begin{array}{l}\text { ATGGGCCACCTGCTAGCTC } \\
\text { ACCTGACACTGCAACCCATT }\end{array}$ & n.d. & $\mathrm{C}$ & - \\
\hline $81 \mathrm{f} / 82 \mathrm{r}$ & rs17669584 & $25,923,740$ & A/G 0.300 & $\begin{array}{l}\text { CTTGGAGACCAACCCACATC } \\
\text { TCGGCAGTCTGAAACATGAC } \\
\end{array}$ & n.d. & A & n.d. \\
\hline $31 \mathrm{f} / 32 \mathrm{r}$ & rs216412 & $25,927,520$ & A/G 0.207 & $\begin{array}{l}\text { GCAGATCTTTGCCTCCCTTT } \\
\text { GAAGCTTCGCCTGCACCT } \\
\end{array}$ & $\mathrm{A} / \mathrm{G}$ & $\mathrm{G}$ & - \\
\hline $31 \mathrm{f} / 32 \mathrm{r}$ & rs170052 & $25,927,544$ & $\mathrm{~A} / \mathrm{C} 0.230$ & $\begin{array}{l}\text { GCAGATCTTTGCCTCCCTTT } \\
\text { GAAGCTTCGCCTGCACCT } \\
\end{array}$ & $\mathrm{C} / \mathrm{A}$ & $\mathrm{C}$ & - \\
\hline $31 \mathrm{f} / 32 \mathrm{r}$ & rs216411 & $25,927,619$ & $\mathrm{C} / \mathrm{T} 0.200$ & $\begin{array}{l}\text { GCAGATCTTTGCCTCCCTTT } \\
\text { GAAGCTTCGCCTGCACCT } \\
\end{array}$ & $\mathrm{T} / \mathrm{C}$ & $\mathrm{C}$ & - \\
\hline $83 \mathrm{f} / 84 \mathrm{r}$ & rs216410 & $25,927,957$ & C/G 0.200 & \begin{tabular}{|l} 
CTTCTGAGCTGTGGTCGTCA \\
AAGACGCAAAGGCCAATAAAA
\end{tabular} & $\mathrm{C} / \mathrm{G}$ & $G$ & - \\
\hline S102/103 & rs426434 & $25,949,479$ & $\mathrm{C} / \mathrm{T} 0.183$ & $\begin{array}{l}\text { CCTCTGCATGTTAACCCTGTAT } \\
\text { GGCTGAACAGTGGCAAAAA }\end{array}$ & $\mathrm{C} / \mathrm{T}$ & $\mathrm{C}$ & $\mathrm{C}$ \\
\hline $85 f / 86 r$ & rs9890961 & $25,952,308$ & $\mathrm{~A} / \mathrm{C} 0.018$ & \begin{tabular}{|l} 
GCGGGGTACCTGTTGACTT \\
TTCAATAATCCCCTTCACGAG \\
\end{tabular} & $\mathrm{C}$ & $\mathrm{C}$ & $\mathrm{C}$ \\
\hline $87 \mathrm{f} / 88 \mathrm{r}$ & \begin{tabular}{|l|} 
rs216440 \\
\end{tabular} & $25,952,435$ & $\mathrm{~A} / \mathrm{T} 0.422$ & $\begin{array}{l}\text { TTGTGGAGGGGAGGATACAC } \\
\text { ACAGGCACATGGGAAAAGTC }\end{array}$ & T/A & $\mathrm{A}$ & $\mathrm{A}$ \\
\hline $13 \mathrm{f} / 14 \mathrm{r}$ & rs7218060 & $27,451,516$ & G/T 0.257 & \begin{tabular}{|l|} 
TCATTATGAATTTTCATGTGATAGAAC \\
GAACACATTGTGGCCTAAAGC
\end{tabular} & $\mathrm{G} / \mathrm{T}$ & $\mathrm{G} / \mathrm{T}$ & - \\
\hline $17 \mathrm{f} / 18 \mathrm{r}$ & rs8081372 & $27,461,882$ & A/G 0.265 & $\begin{array}{l}\text { AGGGGAAGACAGTGGACTTG } \\
\text { TAATGTCGTCTGTGCCCTTG }\end{array}$ & G/A & G/A & $\mathrm{G}$ \\
\hline $37 f / 38 r$ & rs3809786 & $27,463,437$ & A/G 0.271 & \begin{tabular}{|l} 
GGCCAGGAGGGAGTTGTTAC \\
TGGAAAATGGATTCCGAGTCT
\end{tabular} & n.d. & G/A & - \\
\hline $21 \mathrm{f} / 22 \mathrm{r}$ & rs7226186 & $27,468,787$ & A/G 0.252 & \begin{tabular}{|l|} 
TAAGCGAAGTGGGATCTTGG \\
CTCTGCCTCCCAGCCTAGAA \\
\end{tabular} & G/A & $\mathrm{G} / \mathrm{A}$ & - \\
\hline $25 f / 26 r$ & rs9915569 & 27.490 .232 & $\mathrm{~A} / \mathrm{C} 0.274$ & $\begin{array}{l}\text { CACGGCGGCTTAATTCTTTA } \\
\text { GCACTTTCAGTGAGCAATGG } \\
\end{array}$ & n.d. & n.d. & $\mathrm{A}$ \\
\hline $57 f / 58 r$ & rs7220511 & 27.504 .797 & $\mathrm{~A} / \mathrm{G} 0.300$ & $\begin{array}{l}\text { GGATGAGAATATGGAGATATTTGAA } \\
\text { ACAACTACCACCAGCATGGA }\end{array}$ & n.d. & n.d. & G \\
\hline
\end{tabular}

a: according to the Human Genome Assembly, hg18 March 2006, NCBI Build 36.1

n.d.: not determined

b: Lymphocyte DNA from patients UAB-r3302 and UAB-r7332 was investigated. In the case of patient UAB-M1, DNA isolated from melanocyte cultures was analysed. Due to the low amount of DNA obtained from the melanocyte cultures, only a subset of SNPs could be analysed. - : denotes SNP not investigated owing to the limited amount of DNA available. CEU: Utah residents with Northern and Western European ancestry from the

SNPs marked in yellow are located proximal to or at the beginning of NF1-REP A, whereas SNPs marked in blue are located distal to NF1-REP C. 
Supplementary Table S3: Patients with segmental NF1 and identified mosaic NF1 gene mutations

\begin{tabular}{|c|c|}
\hline Patient/ Reference & $\begin{array}{l}\text { NF1 gene mutation identified (first hit) and breakpoint } \\
\text { localization of deletions }\end{array}$ \\
\hline Tinschert et al., [2000] & $\begin{array}{l}\text { large NFI deletion as determined by FISH but the type of deletion } \\
\text { was not further specified }\end{array}$ \\
\hline $\begin{array}{l}\text { SNF1-3/ } \\
\text { Maertens et al., [2007] }\end{array}$ & $\begin{array}{l}\text { atypical NF1 deletion of } 1.8-2.8-\mathrm{Mb} \text {. The proximal deletion } \\
\text { breakpoint is located } 174-353-\mathrm{kb} \text { centromeric to NF1-REP A } \\
\text { whereas the distal breakpoint is located between the telomeric end of } \\
\text { NF1-REP C and position } 27,598,975 \text { (151-kb breakpoint interval). }\end{array}$ \\
\hline $\begin{array}{l}\text { SNF1-2/ } \\
\text { Maertens et al., [2007] }\end{array}$ & $\begin{array}{l}\text { atypical NF1 deletion of } \sim 1.3-\mathrm{Mb} \text { with the proximal breakpoint } \\
\text { located within NF1-REP A and the distal deletion breakpoint located } \\
\text { within the SUZ12 gene }\end{array}$ \\
\hline $\begin{array}{l}\text { SNF1-1/ } \\
\text { Maertens et al., [2007] }\end{array}$ & mutation c.2041C>T (p.R681X) \\
\hline Consoli et al., [2005] & mutation c.5839C >T (p.R1947X) \\
\hline $\begin{array}{l}\text { P067 } \\
\text { This study }\end{array}$ & $\begin{array}{l}\text { type-1 NF1 deletion with breakpoints located within the PRS1 region } \\
\text { of NF1-REPs A and C }\end{array}$ \\
\hline
\end{tabular}

